\title{
Reactive ion etching of tellurite and chalcogenide waveguides using hydrogen, methane, and argon
}

\author{
K. T. Vu ${ }^{a)}$ and S. J. Madden \\ Laser Physics Centre, Research School of Physics and Engineering, Australian National University, \\ Canberra, Australian Capital Territory 0200, Australia
}

(Received 29 August 2010; accepted 28 November 2010; published 5 January 2011)

\begin{abstract}
The authors report in detail on the reactive plasma etching properties of tellurium and demonstrate a high quality etching process using hydrogen, methane, and argon. Very low loss planar ridge waveguides are demonstrated. Optical losses in tellurium dioxide waveguides below $0.1 \mathrm{~dB} / \mathrm{cm}$ in most of the near infrared region of the electromagnetic spectrum and at $1550 \mathrm{~nm}$ have been achieved - the lowest ever reported by more than an order of magnitude and clearly suitable for planar integrated devices. The etch process is also shown to be suitable for chalcogenide glasses which may be of importance in applications such as phase change memory devices and nonlinear integrated optics. (C) 2011 American Vacuum Society. [DOI: 10.1116/1.3528248]
\end{abstract}

\section{INTRODUCTION}

Tellurite glasses are of considerable interest for a broad range of applications in fields such as optical telecommunications, sensing, and defense due to their wealth of excellent optical properties. These glasses are highly transparent from around $400 \mathrm{~nm}$ to $\sim 6 \mu \mathrm{m}$ in the midinfrared, have high acousto-optic figures of merit (three times that of quartz), ${ }^{1}$ the largest optical nonlinearity of any oxide glass (up to $\sim 80$ times that of silica ${ }^{2}$ ), high linear refractive indices (up to 2.2), and low material dispersion. ${ }^{3,4}$ Tellurites have large Raman shifts (up to $1200 \mathrm{~cm}^{-1}$ in some compositions, ${ }^{5,6}$ ) and large Raman gain coefficients $\left(\sim 60\right.$ times silica $\left.{ }^{5,7}\right)$. Poling of tellurite glasses has also led to the largest induced second order nonlinearity in any oxide glass to date. ${ }^{8}$ Tellurite glasses are also excellent hosts for many rare earth ions such as $\mathrm{Er}^{3+}, \mathrm{Tm}^{3+}$, and $\mathrm{Ho}^{3+}$, displaying transitions not seen in silica for example, which are crucial for active in integrated optics components, ${ }^{9,10}$ especially those operating in the midinfrared. Furthermore, tellurite glasses are thermally and mechanically stable. ${ }^{1}$

These properties are well known and extensively exploited in the fields of acousto-optic devices, ${ }^{11}$ fiber based optical amplification, ${ }^{12-15}$ and nonlinear optical processing. ${ }^{16-18}$ However, planar tellurite devices have, until now, proven to be rather problematic. There have been a number of reports ${ }^{17,19-27}$ of planar waveguides fabricated in tellurite glasses using techniques such as UV direct writing, ${ }^{17,19}$ femtosecond laser direct writing, ${ }^{20-22}$ ion exchange, ${ }^{23-25}$ ion implantation, ${ }^{26}$ and sputter etching. ${ }^{27}$ While some of these methods have realized small channel waveguides, propagation losses were high [lowest reported loss of $1.3 \mathrm{~dB} / \mathrm{cm}$ (Ref. 17)] and there are no reports of losses even approaching $0.5 \mathrm{~dB} / \mathrm{cm}$, about the highest allowable value for useful linear or nonlinear optical integrated devices. The best reported result using plasma etching was

\footnotetext{
*No proof corrections received from author prior to publication.

a) Author to whom correspondence should be addressed; electronic mail: khu.vu@anu.edu.au
}

$6.3 \mathrm{~dB} / \mathrm{cm} .{ }^{27}$ Hence, to date, no high quality plasma etching process has been demonstrated for tellurite materials.

Chalcogenide glasses contain chalcogen elements $(\mathrm{S}, \mathrm{Se}$, or $\mathrm{Te}$ ) as substantial components typically covalently bonded to network forming elements such as $\mathrm{Ge}, \mathrm{As}, \mathrm{Sb}$, or Si. These glasses have significant applications ranging from nonvolatile random access memories ${ }^{28}$ to integrated nonlinear optical devices $^{29}$ due to their high optical nonlinearity. The current etching technology to make devices from these materials uses halocarbon gasses such as $\mathrm{CHF}_{3}$ (Ref. 30) or $\mathrm{CF}_{4} \cdot{ }^{31}$ Halogen containing gasses are considered increasingly harmful to the environment. Therefore, an alternative option that uses more friendly and easier to handle gasses would be a big advantage for large scale industrial applications involving these materials.

Plasma etching is a favored method in the fabrication of tellurite and chalcogenide devices due to the chemical reactivity of these materials to, for example, aqueous bases. ${ }^{32,33}$ Furthermore, plasma etching provides good control over the etching process using in situ etch depth monitoring. ${ }^{34}$

In this article, we advance the plasma etching of tellurium oxide and show that it is also useful for chalcogenides. Reactive ion etching (RIE) with different plasma mixtures including trifluoromethane $\left(\mathrm{CHF}_{3}\right)$ and argon, hydrogen and methane, and argon were extensively studied to realize low propagation loss optical waveguides. Planar waveguides with minimum losses below even $0.1 \mathrm{~dB} / \mathrm{cm}$ have been demonstrated as proof of the veracity of the etch process. The same etch recipe is also applied to chalcogenide glass thin films with similar results. It offers an environment friendly alternative to existing etching methods.

\section{TEO $_{2}$ THIN FILM FABRICATION}

Pure $\mathrm{TeO}_{2}$ films were deposited using reactive sputtering of tellurium metal in an argon/oxygen mixture in a manner similar to that of Nayak et al. ${ }^{35}$ The optimum sputtering condition for the stoichiometric state was with a pressure of 5 mTorr, an oxygen flow of 6.4 SCCM (SCCM denotes cubic centimeter per minute at STP), an argon flow of 8.6 SCCM, 


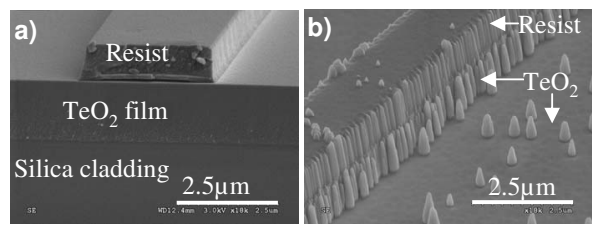

FIG. 1. (a) SEM image of $\mathrm{TeO}_{2}$ waveguide after oxygen etching to remove BARC layer (before $\mathrm{TeO}_{2}$ etching). (b) SEM image of $\mathrm{TeO}_{2}$ waveguide after etching by $\mathrm{CHF}_{3} / \mathrm{Ar}$ plasma.

and a rf power of $150 \mathrm{~W}$. Films were deposited at $1.8 \mu \mathrm{m}$ thickness on $\langle 100\rangle$ oriented $100 \mathrm{~mm}$ silicon wafers with $2 \mu \mathrm{m}$ of thermal oxide as a bottom cladding. The refractive index of the as deposited films was measured using dual angle spectroscopic reflectometer (SCI Filmtek 4000). The refractive index of the film at $1550 \mathrm{~nm}$ was measured as 2.08 , within 0.03 of that of bulk amorphous $\mathrm{TeO}_{2}$. An etch mask was then patterned using standard I-line contact photolithography methods utilizing $0.9 \mu \mathrm{m}$ thick Clariant AZ $701 \mathrm{MiR}$ photoresist and $150 \mathrm{~nm}$ thick Brewer Science XHRiC-16 bottom antireflective coating (BARC). The BARC layer is crucial and also acts as a protective layer during the photoresist development process to avoid wet etching of the $\mathrm{TeO}_{2}$ film. Nominal waveguide widths were $4 \mu \mathrm{m}$. Before etching the $\mathrm{TeO}_{2}$ structures, the BARC layer was removed by exposing the wafer to an oxygen plasma using an Oxford inductively coupled plasma (ICP) Plasmalab 100 system set to $200 \mathrm{~W}$ ICP power, $20 \mathrm{~W}$ forward rf bias chuck power ( $0 \mathrm{~W}$ reflected, $120 \mathrm{~V}$ dc bias voltage), 10 mTorr pressure, and 30 SCCM oxygen gas flow. The achieved structure is shown on Fig. 1(a). The photoresist mask has vertical sidewalls. The bowing effect visible in the BARC layer is due to cleaving.

\section{PLASMA ETCHING}

\section{A. $\mathrm{CHF}_{3} / \mathrm{Ar}$ based etching of $\mathrm{TeO}_{2}$}

Halogen containing gasses such as $\mathrm{CHF}_{3}$ and $\mathrm{CF}_{4}$ have been used for etching a number of materials ${ }^{36}$ including silica ${ }^{37}$ and chalcogenide glasses. ${ }^{38}$ Plasmas from these gasses produce active fluorocarbon and fluorine radicals. The fluorine radical reacts with many compounds to form volatile products. ${ }^{39}$ The $\mathrm{CF}_{x}(x=1,2,3)$ fluorocarbon radicals, especially $\mathrm{CF}_{2}$, form polymer which is deposited on the sidewalls to passivate the waveguide structure producing vertical sidewalls. ${ }^{40}$ Therefore, a $\mathrm{TeO}_{2}$ film was first etched using a mixture of $\mathrm{CHF}_{3}$ and $\mathrm{Ar}$ in an ICP plasma system under the following conditions: 50 SCCM $\mathrm{CHF}_{3}$ flow, 50 SCCM Ar flow, $150 \mathrm{~W}$ forward power, and $30 \mathrm{~m}$ Torr chamber pressure. The etch rate monitor indicated the etch rate at typically between $50-60 \mathrm{~nm} / \mathrm{min}$. The scanning electron microscope (SEM) image of the etched surface after $15 \mathrm{~min}$ is shown on Fig. 1(b). Beside the clear visibility of a two layer structure of $\mathrm{TeO}_{2}$ underneath and the photoresist layer on top, the side walls of the waveguide structure are vertical but rough. There are also regions where there is significant columnar growth. Even though tellurium hexafluoride- $\mathrm{TeF}_{6}$ is a vola- tile compound, tellurium tetrafluoride- $\mathrm{TeF}_{4}$, which has melting and boiling points at 129 and $195{ }^{\circ} \mathrm{C}$, respectively, is not volatile. $^{39}$ This results in redeposition and micromasking making the side walls rough and forming columns on the surface. Other compounds of tellurium and halogen elements also have high boiling points. Therefore, for tellurium oxide films, halogen containing plasmas appear unsuitable to obtain high quality etched structures.

\section{B. $\mathrm{CH}_{4} / \mathrm{H}_{2} / \mathrm{Ar}$ based etching of $\mathrm{TeO}_{2}$}

The idea behind $\mathrm{CH}_{4}$ and $\mathrm{H}_{2}$ based etching is to form hydrides and metal-organic compounds. $\mathrm{H}_{2}$ and $\mathrm{CH}_{4}$ are easier to handle, less toxic, less corrosive, and more environment friendly than halocarbon gasses (especially after abatement). They have been used in RIE for a range of semiconducting compounds such as groups III-V, ${ }^{41-43}$ II-VI, ${ }^{4,45}$ and IV-VI. ${ }^{46} \mathrm{CH}_{4}$ contributes to the etching process in two ways. The first is to form volatile metal-organic compounds. The second is to create active radicals $\mathrm{C}_{n} \mathrm{H}_{m}$ and ions $\mathrm{C}_{n} \mathrm{H}_{m}{ }^{+}$such as $\mathrm{CH}_{3}$ and $\mathrm{CH}_{2}{ }^{+}$(Refs. 47 and 48) to form polymers that help passivate the sidewalls of the masked areas and increase the selectivity and anisotropy of the etching process. The combinations of tellurium dioxide with highly reactive hydrogen and methane radicals form all volatile compounds such as tellurium hydride- $\mathrm{TeH}_{2}{ }^{49}$ dimethyl tellurite- $\mathrm{Te}\left(\mathrm{CH}_{3}\right)_{2},{ }^{39}$ and $\mathrm{H}_{2} \mathrm{O}$. Some of the possible chemical reactions are as follows: ${ }^{42,46}$

$$
\begin{aligned}
& \mathrm{TeO}_{2}+3 \mathrm{H}_{2} \rightarrow \mathrm{TeH}_{2}+2 \mathrm{H}_{2} \mathrm{O} \\
& \mathrm{TeO}_{2}+2 \mathrm{H}+2 \mathrm{H}_{2} \rightarrow \mathrm{TeH}_{2}+2 \mathrm{H}_{2} \mathrm{O} \\
& 2 \mathrm{TeO}_{2}+10 \mathrm{H}+2 \mathrm{CH}_{3} \rightarrow \mathrm{TeH}_{2}+4 \mathrm{H}_{2} \mathrm{O}+\mathrm{Te}\left(\mathrm{CH}_{3}\right)_{2} \\
& 2 \mathrm{TeO}_{2}+2 \mathrm{H}+4 \mathrm{H}_{2}+2 \mathrm{CH}_{3} \rightarrow \mathrm{TeH}_{2}+4 \mathrm{H}_{2} \mathrm{O}+\mathrm{Te}\left(\mathrm{CH}_{3}\right)_{2} .
\end{aligned}
$$

The reactions (1)-(4) are just a small sample of the possible reactions that can occur on the surface of the films due to the fact that there a large number of radicals of hydrogen and methane generated in the plasma. ${ }^{47,48,50}$ There are also polymerization reactions of organic compounds originated from methane. Argon is added to the mix as an additive to stabilize the plasma and increases the electron density. ${ }^{34}$ The argon ions are also accelerated under the bias electric field toward the film to sputter deposited polymers on the etched horizontal surfaces.

\section{Design of experiment: Screening}

Since there are many etching parameters that can be varied, the design of experiments (DOEs) method was used to screen the etch characteristics of $\mathrm{TeO}_{2}$ in $\mathrm{H}_{2}, \mathrm{CH}_{4}$, and $\mathrm{Ar}$ plasma and to determine the best condition. The linear Plackett-Burman design ${ }^{51}$ was applied to five factors including pressure, Ar flow, $\mathrm{H}_{2}$ flow, $\mathrm{CH}_{4}$ flow, and rf power. Table I shows the detailed parameters of 14 randomized runs including two repeats for consistency monitoring. The lower 
TABLE I. Experiment design for $\mathrm{TeO}_{2}$ etching using RIE with $\mathrm{H}_{2}, \mathrm{CH}_{4}$, and Ar. The responses 0-3 correspond to from bad to very good etch.

\begin{tabular}{ccccccccc}
\hline \hline & $\begin{array}{c}\text { Pressure } \\
\text { Experiment No. }\end{array}$ & $\begin{array}{c}\mathrm{Ar} \\
(\mathrm{mTorr})\end{array}$ & $\begin{array}{c}\mathrm{H}_{2} \\
(\mathrm{SCCM})\end{array}$ & $\begin{array}{c}\mathrm{CH}_{4} \\
(\mathrm{SCCM})\end{array}$ & $\begin{array}{c}\text { Power } \\
(\mathrm{SCCM})\end{array}$ & $\begin{array}{c}\mathrm{d} \text { dc bias voltage } \\
(\mathrm{V})\end{array}$ & Observation & Response \\
\hline 1 & 30 & 60 & 30 & 5 & 300 & 185 & Rough, damaged & 1 \\
2 & 30 & 30 & 10 & 5 & 300 & 196 & Rough, resist damaged & 1 \\
3 & 30 & 60 & 10 & 20 & 300 & 192 & Polymer build up & 0 \\
4 & 15 & 60 & 30 & 5 & 300 & 179 & Etched, resist damaged & 2 \\
5 & 22.5 & 45 & 20 & 12.5 & 250 & 165 & Polymer build up & 0 \\
6 & 22.5 & 45 & 20 & 12.5 & 250 & 166 & Polymer build up & 0 \\
7 & 30 & 30 & 30 & 20 & 200 & 139 & Polymer build up & 0 \\
8 & 30 & 30 & 30 & 5 & 200 & 143 & Good etch & 3 \\
9 & 15 & 60 & 30 & 20 & 200 & 140 & Etched, resist damaged & 1 \\
10 & 30 & 60 & 10 & 20 & 200 & 150 & Polymer build up & 0 \\
11 & 15 & 30 & 30 & 20 & 300 & 174 & Etched, resist damaged & 2 \\
12 & 15 & 30 & 10 & 20 & 300 & 181 & Polymer build up & 1 \\
13 & 15 & 30 & 10 & 5 & 200 & 149 & Etched, resist damaged & 2 \\
14 & 15 & 60 & 10 & 5 & 200 & 152 & Etched, polymer build up & 2 \\
\hline
\end{tabular}

and upper limits for the variables are 15/30 mTorr for pressure, 30/60 SCCM for Ar, 10/30 SCCM for $\mathrm{H}_{2}, 5 / 20$ SCCM for $\mathrm{CH}_{4}$, and $200 / 300 \mathrm{~W}$ for $\mathrm{rf}$ power. Each sample was around $1 \times 1 \mathrm{~cm}^{2}$ and was etched for $3 \mathrm{~min}$ in separate experiments. The etching experiments were conducted in an Oxford Plasmalab 80 RIE system (without an in situ etch rate monitor). A series of experiments with the parameters tabulated on Table I was carried out. A SEM, Hitachi S4300, was used to examine the profile and the morphology of the etched waveguides. Quantitative responses can be scored based on the observation of the SEM images as follows: 0 for no etching or a lot of polymerization, 1 for rough etching or photoresist damage, 2 for some degree of smooth etching, and 3 for good etching. The last column of Table I shows the values of the responses for each etching condition.

The response of etching process against the parameters is highly nonlinear. It is therefore not possible to apply the linear or quadratic fitting assumed in common DOE methodologies to the results. However, a conclusion from this series of experiments is that in experiment number 8 on Table I with 30 mTorr pressure, $5 \mathrm{SCCM} \mathrm{CH}_{4}, 30 \mathrm{SCCM} \mathrm{H}_{2}$ flow, $30 \mathrm{SCCM}$ Ar, and $200 \mathrm{~W}$ produces the best result. From this point, if much more $\mathrm{CH}_{4}$ or higher pressure is introduced, high level polymerization occurs leading to no etching or polymer build up. However, since the response function was qualitative, further investigation was required to narrow down the best operating conditions.

\section{Design of experiment: Fine tuning}

Two sets of samples with dimension of around 1 $\times 1 \mathrm{~cm}^{2}$ were etched: one with varying $\mathrm{CH}_{4}$ flow from 3 to 10 SCCM while keeping all other parameters fixed $(5 \mathrm{~min}$ etching time, 30 mTorr pressure, 30 SCCM Ar, 30 SCCM $\mathrm{H}_{2}$, and $200 \mathrm{~W}$ rf power) and another set with varying pressure from 20 to $80 \mathrm{mTorr}$ while keeping all other parameters fixed (5 min etching time, $30 \mathrm{SCCM} \mathrm{Ar,} 30 \mathrm{SCCM} \mathrm{H} \mathrm{H}_{2}, 5$ $\mathrm{SCCM} \mathrm{CH}_{4}$, and $200 \mathrm{~W}$ rf power). The etched samples were then imaged using a Hitachi S4300 electron microscope. Figure 2 shows the SEM images of the etched samples for varying $\mathrm{CH}_{4}$ flows. In all cases, the etched surfaces are clean and smooth. The differences in the four images are in the etched depths and the degree of isotropic etching (horizontal etched depth divided by the vertical etched depth). ${ }^{52}$ The waveguide in Fig. 2(b) corresponds to the $5 \mathrm{SCCM} \mathrm{CH}_{4}$ flow and shows no horizontal etching whatsoever.

The $\mathrm{TeO}_{2}$ etching rate, photoresist etching rate, and degree of isotropic etching were chosen as the response functions. These response functions are plotted on Fig. 3. Since $\mathrm{CH}_{4}$ can form polymer not only to passivate the vertical side walls, but also on the photoresist layer, the photoresist etching rate can become negative due to polymer deposition as shown in Figs. 3(a) and 3(c). The $\mathrm{TeO}_{2}$ etching rate is generally greater than $100 \mathrm{~nm} / \mathrm{min}$ for all conditions. There are dips in the etching rate and undercut with varying $\mathrm{CH}_{4}$ flow. The optimum point for low undercutting is with 5 SCCM $\mathrm{CH}_{4}$ flow. With increasing chamber pressure, the etching rate

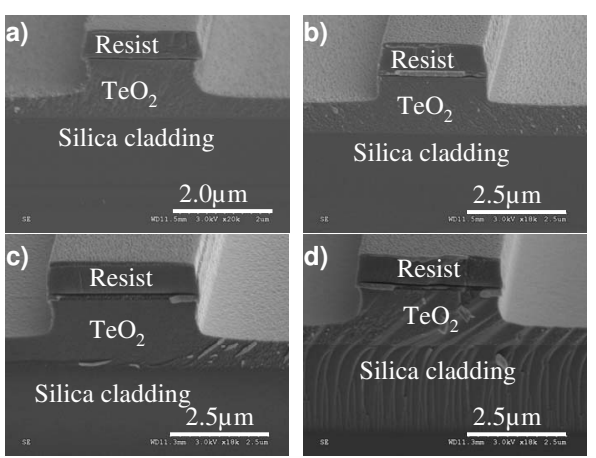

FIG. 2. Effect of varying $\mathrm{CH}_{4}$ flow on the etched profile. The etching parameters were the following: $5 \mathrm{~min}$ etching time, $30 \mathrm{mTorr}$ pressure, 30 SCCM Ar, $30 \mathrm{SCCM} \mathrm{H}$, and $200 \mathrm{~W}$ rf power. The flow of $\mathrm{CH}_{4}$ was varied as follows: (a) $3 \mathrm{SCCM}$, (b) 5 SCCM, (c) 7 SCCM, and (d) 10 SCCM. The sample in (d) has bad cleaving and produced chipping on the facet. 

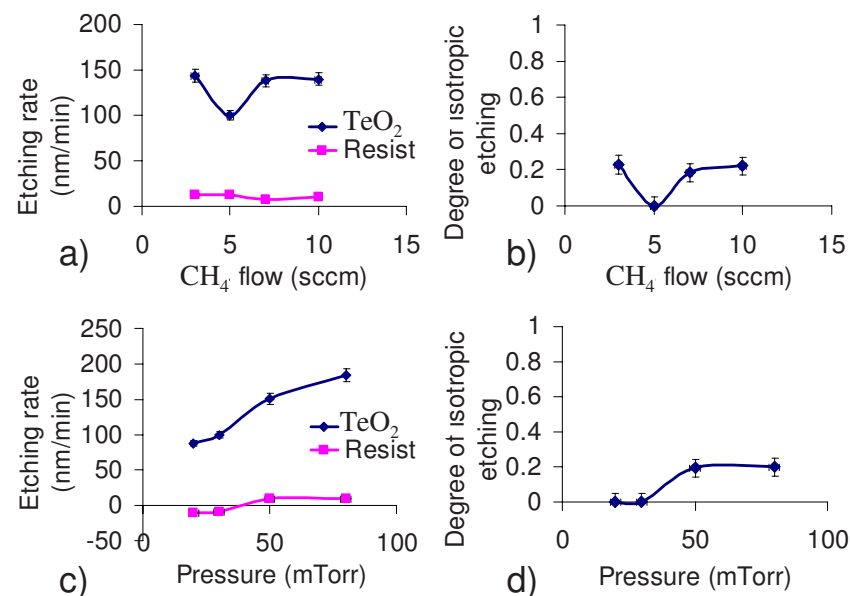

FIG. 3. (Color online) Response functions against the varied parameters. (a) Etching rates of $\mathrm{TeO}_{2}$ and photoresist at various $\mathrm{CH}_{4}$ flows. (b) Degree of isotropic etching at various $\mathrm{CH}_{4}$ flows. (c) Etching rates of $\mathrm{TeO}_{2}$ and photoresist at various pressures. (d) Degree of isotropic etching at various pressures.

increases but the selectivity and undercutting get worse. Therefore, the optimum operating pressure is at $30 \mathrm{mTorr}$.

The best etching condition is with 30 mTorr pressure, 30 SCCM Ar, $30 \mathrm{SCCM} \mathrm{H}_{2}, 5 \mathrm{SCCM} \mathrm{CH}_{4}$, and $200 \mathrm{~W}$ rf power. Figure 4(a) shows the SEM image for this particular etching condition. This etching condition gives not only smooth etched surfaces with rms roughness of $0.5 \mathrm{~nm}$ as measured by atomic force microscopy but also vertical side walls.

\section{C. $\mathrm{CH}_{4} / \mathrm{H}_{2} / \mathrm{Ar}$ based etching of chalcogenide glass thin films}

A $\mathrm{Ge}_{11.5} \mathrm{As}_{21.5} \mathrm{Se}_{67}$ thin film was deposited using thermal evaporation similar to Jarvis et al. ${ }^{53}$ The film was then patterned with the same steps as the previously described $\mathrm{TeO}_{2}$ films. The same etching condition as in experiment 8 on Table I was used to etch the patterned $\mathrm{Ge}_{11.5} \mathrm{As}_{21.5} \mathrm{Se}_{67}$ chalcogenide glass film. The film was etched for $25 \mathrm{~min}$. The etching rate was $40 \mathrm{~nm} / \mathrm{min}$. The SEM image of the etched waveguide is shown on Fig. 4(b). Again, the etched waveguide has smooth surfaces and vertical sidewalls. This establishes that the developed recipe can cleanly remove $\mathrm{Te}, \mathrm{Ge}$, As, Se, and all major components of technologically important chalcogenides such as GST $\left(\mathrm{Ge}_{2} \mathrm{Sb}_{2} \mathrm{Te}_{5}\right)$ that is used in phase change random access memory and optical disks. Etching of GST sample was not carried out due to the unavailability of the films. Etching of GST is possible due to

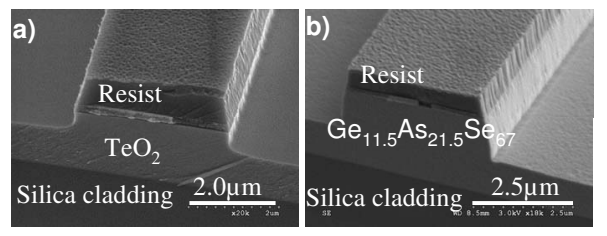

FIG. 4. Etching of (a) $\mathrm{TeO}_{2}$ and (b) $\mathrm{Ge}_{11.5} \mathrm{As}_{21.5} \mathrm{Se}_{67}$ glass thin films using RIE with $\mathrm{H}_{2} / \mathrm{CH}_{4} / \mathrm{Ar}$ plasma mix.

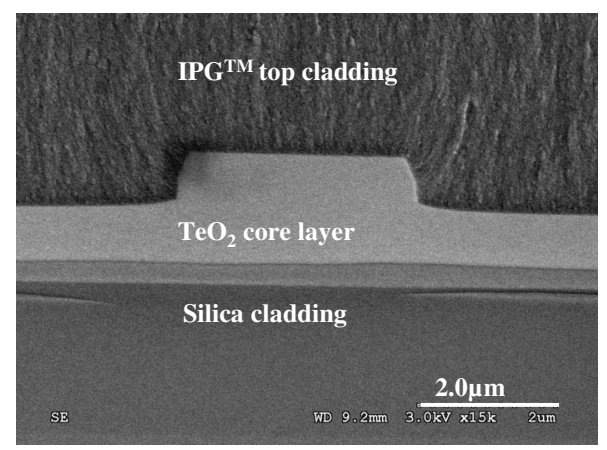

FIG. 5. SEM micrograph of cleaved finished waveguide in the $1.8 \mu \mathrm{m}$ thick tellurium oxide film. An apparent layer between the $\mathrm{TeO}_{2}$ and silica is an artifact produced by cleaving.

the fact that $\mathrm{Sb}$ has very similar chemical properties to As (particularly a volatile hydride) that can be clearly etched by $\mathrm{CH}_{4} / \mathrm{H}_{2} / \mathrm{Ar}$ gas mix. The etching gasses used here are much more environment friendly than the alternatives such as $\mathrm{HBr} / \mathrm{Ar}$ (Ref. 54) or $\mathrm{CHF}_{3} / \mathrm{O}_{2}$ (Ref. 55) as they are not halogenated and any remnant $\mathrm{CH}_{4}$ can be abated by simple combustion at the exhaust scrubber to remove any greenhouse contamination.

\section{WAVEGUIDE CHARACTERIZATION}

A full 4 in. $(\sim 100 \mathrm{~mm})$ wafer coated with $1.8 \mu \mathrm{m}$ thick $\mathrm{TeO}_{2}$ was patterned and etched using the best condition as described above. The etched waveguide has a rib $0.8 \mu \mathrm{m}$ high. Postetch resist removal was accomplished by an oxygen plasma strip. The waveguides were then clad with a $15 \mu \mathrm{m}$ thick film of UV cured inorganic polymer glass (RPO Pty Ltd., IPG ${ }^{\mathrm{TM}}$ ) which has a refractive index of 1.51 at $1550 \mathrm{~nm}$. End facets were then prepared on the waveguides by cleaving the silicon substrate with a diamond scriber. The resulting waveguide chip was approximately 6 $\mathrm{cm}$ wide and $7.8 \mathrm{~cm}$ long. Figure 5 shows a SEM micrograph of the end facet of a finished waveguide.

Insertion loss measurements were made using either an external cavity laser based system or a white light source/ optical spectrum analyzer based system. Fiber coupling to the waveguide chips was accomplished using antireflection coated fiber taper lenses with a $2.5 \mu \mathrm{m} 1 / e^{2}$ mode field diameter at $1550 \mathrm{~nm}$ to suppress the Fabry-Perot cavity between the waveguide and fiber end faces. Modeling of the $4 \mu \mathrm{m}$ waveguides used here with the full vector generic finite difference mode of the C2V OLYMPIOS software resulted in a calculated overlap loss to the fiber tapered lens of 0.71 $\mathrm{dB}(\mathrm{TE})$ and $0.79 \mathrm{~dB}(\mathrm{TM})$ per end at $1550 \mathrm{~nm}$. Polarization dependent loss (PDL) data were gathered using a scanning polarization controller. Wideband measurements were made using a fiber coupled mercury arc lamp and optical spectrum analyzer operated with a $10 \mathrm{~nm}$ resolution bandwidth to smooth out the chip Fabry-Perot resonances.

Figure 6 shows the insertion loss data after normalization through the fiber tapered lens for a typical $4 \mu \mathrm{m}$ wide waveguide of $7.8 \mathrm{~cm}$ length from 600 to $1700 \mathrm{~nm}$ measured with 


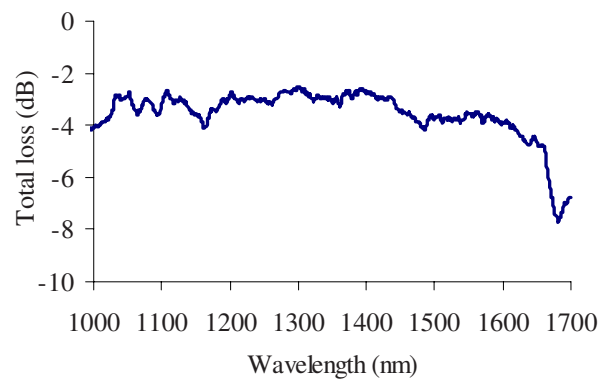

FIG. 6. (Color online) Measured wideband fiber to fiber insertion loss for 7.8 cm long, $4 \mu \mathrm{m}$ wide $\mathrm{TeO}_{2}$ waveguide.

the arc lamp source. Normalized spectra were recorded before and after the measurement to eliminate the source drift, and there was a measurement uncertainty of about $0.3 \mathrm{~dB}$ from fiber connector insertion repeatability induced during the alignment procedures.

The propagation loss was calculated using standard methods. The average of minimum observed total insertion loss between 1300 and $1400 \mathrm{~nm}$ in Fig. 6 was $2.8 \mathrm{~dB}$. The total insertion loss at $1550 \mathrm{~nm}$ was $3.5 \mathrm{~dB}$. The laser based measurement verified that from the optical spectrum analyzer at $1550 \mathrm{~nm}$ to within $0.05 \mathrm{~dB}$. These losses include $1.5 \mathrm{~dB}$ of modal mismatch averaged between the polarizations, $1 \mathrm{~dB}$ due to reflections at both ends (calculated from the computed mode fields and effective indices using a plane wave decomposition method $^{56}$ ), and propagation loss over $7.8 \mathrm{~cm}$ of waveguide length. Therefore, the lowest propagation loss was $0.3 \pm 0.3 \mathrm{~dB}(0.04 \pm 0.04 \mathrm{~dB} / \mathrm{cm})$ and the propagation loss at $1550 \mathrm{~nm}$ was $1.0 \pm 0.3 \mathrm{~dB}(0.12 \pm 0.04 \mathrm{~dB} / \mathrm{cm})$. These low propagation losses were also confirmed by the Fabry-Perot method at $1550 \mathrm{~nm}^{57}$ The fabricated waveguides have low propagation loss for the wavelength range from 1 to $1.5 \mu \mathrm{m}$ more than an order of magnitude better than the best previously reported results ${ }^{17}$ and a two order of magnitude improvement over the best prior plasma etched waveguides ${ }^{27}$ thereby demonstrating the quality of the etching process. The connector induced measurement uncertainty is of the same order as the total measured propagation losses and therefore prevents the derivation of an accurate loss figure, but it is clear that the losses are very low indeed. The nonflat nature of the response, we believe, is attributable to mode coupling and beating phenomena which generate wavelength dependent coupling effects as the waveguides support three modes at $1550 \mathrm{~nm}$ (more at shorter wavelengths) and the input fibers become multimode below $\sim 1250 \mathrm{~nm}$. Measured PDL for the waveguides was $0.35 \mathrm{~dB}$ total at $1550 \mathrm{~nm}$ including a measurement system PDL of $0.13 \mathrm{~dB}$, which compares favorably with the predicted $\sim 0.2 \mathrm{~dB}$ PDL from mode overlap losses noted above.

\section{CONCLUSIONS}

Tellurite and chacolgenide glasses are important candidates for integrated optoelectronic applications. Fabrication techniques for these glasses play a very important role in their research and development. We have investigated the etching of tellurium dioxide waveguides using $\mathrm{CHF}_{3} / \mathrm{Ar}$ and $\mathrm{CH}_{4} / \mathrm{H}_{2} / \mathrm{Ar}$ gas mixtures. The redeposition of nonvolatile products prevents the $\mathrm{CHF}_{3} / \mathrm{Ar}$ gas mixture being a high quality etching option for $\mathrm{TeO}_{2}$. However, the $\mathrm{CH}_{4} / \mathrm{H}_{2} / \mathrm{Ar}$ mixture was extensively studied and confirmed as a versatile choice for both group of glasses. We have demonstrated tellurium oxide planar rib waveguides using reactive rf sputtering and $\mathrm{CH}_{4} / \mathrm{H}_{2} / \mathrm{Ar}$ RIE with minimum losses below 0.1 $\mathrm{dB} / \mathrm{cm}$, the lowest ever reported by a factor exceeding ten times. The etch recipe is also applicable to chalcogenide glasses.

\section{ACKNOWLEDGMENT}

The support of the Australian Research Council through its Discovery Grant Program is gratefully acknowledged (Grant No. DP070333).

${ }^{1}$ R. A. H. El-Mallawany, Tellurite Glasses Handbook: Physical Properties and Data (CRC, Boca Raton, FL, 2002).

${ }^{2}$ B. Jeansannetas et al., J. Solid State Chem. 146, 329 (1999).

${ }^{3}$ D. A. Gaponov and A. S. Biryukov, Quantum Electron. 36, 343 (2006). ${ }^{4}$ G. Ghosh, J. Am. Ceram. Soc. 78, 2828 (1995).

${ }^{5}$ R. Jose and Y. Ohishi, Proceedings of Optical Components and Materials IV (SPIE, San Jose, CA, 2007), p. 64690.

${ }^{6}$ G. S. Murugan, T. Suzuki, and Y. Ohishi, Appl. Phys. Lett. 86, 221109 (2005).

${ }^{7}$ R. Jose and Y. Ohishi, Appl. Phys. Lett. 90, 211104 (2007).

${ }^{8}$ L. R. P. Kassab, R. A. Pinto, R. A. Kobayashi, M. Piasecki, P. Bragiel, and I. V. Kityk, Opt. Commun. 274, 461 (2007).

${ }^{9}$ E. B. Intyushin and V. A. Novikov, Thin Solid Films 516, 4194 (2008).

${ }^{10}$ A. Jha, S. Shaoxiong, H. Li Hui, and P. Joshi, J. Opt. 33, 157 (2004).

${ }^{11}$ N. Uchida and Y. Ohmachi, J. Appl. Phys. 40, 4692 (1969).

${ }^{12}$ S. Shen, A. Jha, X. Liu, M. Naftaly, K. Bindra, H. J. Bookey, and A. K. Kar, J. Am. Ceram. Soc. 85, 1391 (2002).

${ }^{13}$ S. Shen, L. Huang, P. Joshi, and A. Jha, Proceedings of OSA Trends in Optics and Photonics Series (OSA, Washington, DC, 2004), p. 387.

${ }^{14}$ A. Mori and Y. Ohishi, Proceedings of Optical Fiber Communication (IEEE, San Jose, CA, 1998), p. 97.

${ }^{15}$ S. Q. Man, E. Y. B. Pun, and P. S. Chung, Opt. Commun. 168, 369 (1999).

${ }^{16}$ A. Mori, H. Masuda, K. Shikano, K. Oikawa, K. Kato, and M. Shimizu, Electron. Lett. 37, 1442 (2001).

${ }^{17}$ E. Chierici, M. C. Didavide, A. Moro, O. Rossotto, L. Tallone, and E. Monchiero, Proceedings of IEEE/LEOS Workshop on Fibre and Optical Passive Components (IEEE, Piscataway, NJ, 2002), p. 29.

${ }^{18}$ P. Domachuk, N. A. Wolchover, M. Cronin-Golomb, A. Wang, A. K. George, C. M. B. Cordeiro, J. C. Knight, and F. G. Omenetto, Opt. Express 16, 7161 (2008).

${ }^{19}$ E. Monchiero, D. Milanese, M. Ferraris, L. Tallone, and E. Chierici, Proceedings of the 19th Congress of the International Commission for Optics: Optics for the Quality of Life (SPIE, Firenze, Italy, 2003), p. 135.

${ }^{20}$ Y. Tokuda, M. Saito, M. Takahashi, K. Yamada, W. Watanabe, K. Itoh, and T. Yoko, J. Non-Cryst. Solids 326-327, 472 (2003).

${ }^{21}$ P. Nandi, G. Jose, C. Jayakrishnan, S. Debbarma, K. Chalapathi, K. Alti, A. K. Dharmadhikari, J. A. Dharmadhikari, and D. Mathur, Opt. Express 14, 12145 (2006).

${ }^{22}$ T. T. Fernandez, G. Della Valle, R. Osellame, G. Jose, N. Chiodo, A. Jha, and P. Laporta, Opt. Express 16, 15198 (2008).

${ }^{23}$ G. N. Conti, V. K. Tikhomirov, M. Bettinelli, S. Berneschi, M. Brenci, B. Chen, S. Pelli, and A. Speghini, Opt. Eng. 42, 2805 (2003).

${ }^{24}$ G. N. Conti, S. Berneschi, M. Bettinelli, M. Brenci, B. Chen, S. Pelli, A. Speghini, and G. C. Righini, J. Non-Cryst. Solids 345-346, 343 (2004).

${ }^{25}$ Y. Ding, S. Jiang, T. Luo, Y. Hu, and N. Peyghambarian, Proceedings of Rare-Earth-Doped Materials and Devices V (Society of Photo-Optical Instrumentation Engineers, San Jose, CA, 2001), p. 23.

${ }^{26}$ S. Berneschi et al., Appl. Phys. Lett. 90, 121136 (2007).

${ }^{27}$ S. M. Pietralunga, M. Lanata, M. Fere, D. Piccinin, G. Cusmai, M. Torregiani, and M. Martinelli, Opt. Express 16, 21662 (2008). 
${ }^{28}$ B. Prince, Proceedings of 2005 Non-Volatile Memory Technology Symposium (IEEE Computer Society, Dallas, TX, 2005), p. 55.

${ }^{29}$ M. D. Pelusi et al., IEEE J. Sel. Top. Quantum Electron. 14, 529 (2008).

${ }^{30}$ D.-Y. Choi, S. Maden, A. Rode, R. Wang, and B. Luther-Davies, J. NonCryst. Solids 354, 3179 (2008).

${ }^{31}$ Y. Ruan, W. Li, R. Jarvis, N. Madsen, A. Rode, and B. Luther-Davies, Opt. Express 12, 5140 (2004).

${ }^{32}$ M. D. O’Donnell, D. Furniss, V. K. Tikhomirov, D. Briggs, E. F. Smith, and A. B. Seddon, J. Mater. Res. 22, 1673 (2007).

${ }^{33}$ L. Su, C. J. Rowlands, T. H. Lee, and S. R. Elliott, Electron. Lett. 44, 472 (2008).

${ }^{34}$ C. D. W. Wilkinson and M. Rahman, Philos. Trans. R. Soc. London, Ser. A 362, 125 (2004).

${ }^{35}$ R. Nayak, V. Gupta, A. L. Dawar, and K. Sreenivas, Thin Solid Films 445, 118 (2003).

${ }^{36}$ N. Layadi, J. I. Colonell, and J. T.-C. Lee, Bell Labs Tech. J. 4, 155 (1999).

${ }^{37}$ H. Gerung, C. J. Brinker, S. R. J. Brueck, and S. M. Han, J. Vac. Sci. Technol. A 23, 347 (2005).

${ }^{38}$ D.-Y. Choi, S. Madden, A. Rode, R. Wang, and B. Luther-Davies, J. Appl. Phys. 104, 113305 (2008).

${ }^{39}$ R. D. Lide, CRC Handbook of Chemistry and Physics, 88th ed. (CRC, Boca Raton, FL, 2007).

${ }^{40}$ G. Cunge and J. P. Booth, J. Appl. Phys. 85, 3952 (1999).

${ }^{41}$ R. Cheung, S. Thoms, S. P. Beamont, S. P. Doughty, V. Law, and C. D. W. Wilkinson, Electron. Lett. 23, 857 (1987).
${ }^{42}$ A. Semu and P. Silverberg, Semicond. Sci. Technol. 6, 287 (1991).

${ }^{43}$ L. Henry, C. Vaudry, and P. Granjoux, Electron. Lett. 23, 1253 (1987).

${ }^{44}$ M. A. Foad, C. D. W. Wilkinson, C. Dunscomb, and R. H. Williams, Appl. Phys. Lett. 60, 2531 (1992).

${ }^{45}$ S. J. Pearton and F. Ren, J. Mater. Sci.: Mater. Electron. 5, 1 (1994).

${ }^{46}$ T. Schwarzl, W. Heiss, G. Kocher-Oberlehner, and G. Springholz, Semicond. Sci. Technol. 14, L11 (1999).

${ }^{47}$ H. Toyoda, H. Kojima, and H. Sugai, Appl. Phys. Lett. 54, 1507 (1989).

${ }^{48}$ Y. Feurprier, C. Cardinaud, B. Grolleau, and G. Turban, Plasma Sources Sci. Technol. 6, 561 (1997).

${ }^{49}$ M. A. Foad et al., Semicond. Sci. Technol. 6, A115 (1991).

${ }^{50}$ Y. Yamashita, H. Toyoda, and H. Sugai, Jpn. J. Appl. Phys., Part 2 28, L1647 (1989).

${ }^{51}$ STATSOFT, http://www.statsoft.com/textbook/experimental-design/.

${ }^{52}$ D. L. Flamm and V. M. Donnelly, Plasma Chem. Plasma Process. 1, 317 (1981).

${ }^{53}$ R. A. Jarvis, R. P. Wang, A. V. Rode, C. Zha, and B. Luther-Davies, J. Non-Cryst. Solids 353, 947 (2007).

${ }^{54}$ J. W. Lee, H. N. Cho, S. R. Min, and C. W. Chung, Integr. Ferroelectr. 90, 95 (2007).

${ }^{55}$ G. Feng, B. Liu, Z. Song, S. Feng, and B. Chen, Electrochem. Solid-State Lett. 10, D47 (2007).

${ }^{56}$ R. H. Clarke, Bell Syst. Tech. J. 62, 2885 (1983).

${ }^{57}$ G. Tittelbach, B. Richter, W. Karthe, and J. Opt, Pure Appl. Opt. 2, 683 (1993). 